\title{
XII.
}

\section{Veber Classification der Geisteskranklieiten und über die essentielle Verschiedenheit paralytischer und gewisser epileptischer Blödsinnsformen, erläutert an einem Falle von Porencephalie.}

\author{
Von Dr. Franz Meschede, \\ zweitem Arzte der Provinzial-Irren-Heil- und Pflege-Anstalt und des \\ Landkrankenhauses zu Schwetz.
}

(Hierzu Taf. I.)

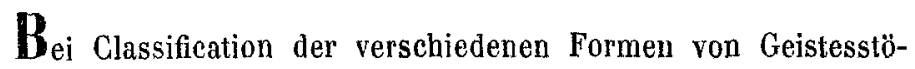
rung hat man sich mit Vorliebe an den In halt der Aeusserungen und an das äussere Verhalten der Gestörten gehalten. Es ist dieses leicht begreiflich, wenn man bedenkt, dass zunächst der Contrast auffallen muss, in welchem die irren Reden mit der Wirklichkeit stehen und dass sich der Grad des praktischen Interesses seitens der bürgerlichen Gesellschaft vorwiegend nacb der Art und Weise bestimmt, wie die Handlungen der Gestörten in die gesellschaftlichen Beziehungen und Ordnungen eingreifen. Nun aher ist der Inhalt der Wahnvorstellungen ein so mannichfaltiger, aus der Summe aller möglichen Ideen, aus der ganzen Lebensund Weltgeschichte geschöpfter, und die Richtungen und Zielpunkte der anomalen Triebe sind ebenso zahlreich, als es Affecte und Leidenschaften erregende Dinge in der Welt gibt, so dass hier für die Construction von Krankheitsspecies ein unerschöpflich reiches Material dargeboten erscheint. Dieses Material ist denn auch in ausgiebigster Weise ausgebeutet worden. Man hat nach dem Inhalte der Wabnvorstellungen und nach der besonderen Richtung der Triebe eine ganze Reihe von Manieen und Wahnsinnsformen ereirt, dieselben mit besonderen Namen belegt und so beglaubigt in das nosologische System der Geisteskrankheiten eingefügt. Dieses Verfahren, die Nosologie der psychiseben Krankheiten zu be- 
Pig $A$

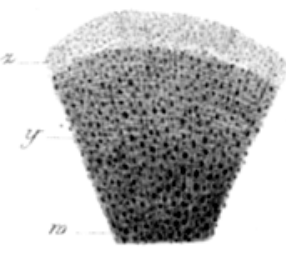

Fig. $B$.

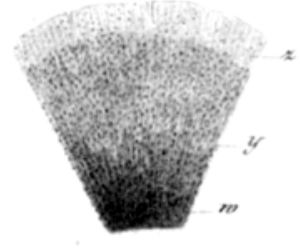

a

\%

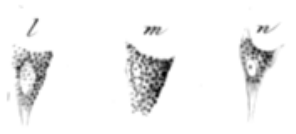

(2)

襍繁穴
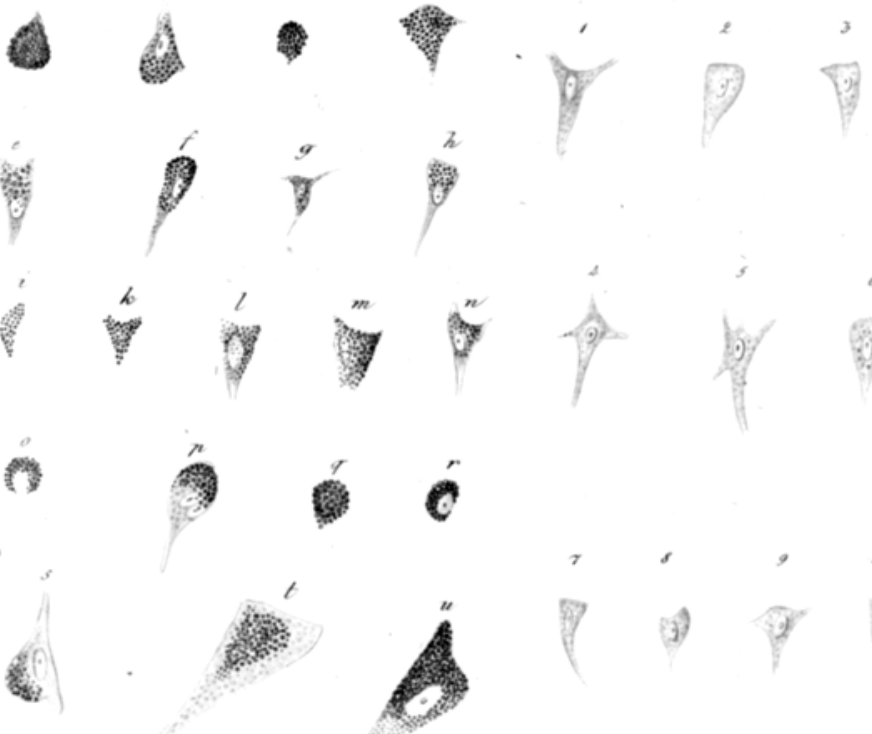

(3)<smiles>C1CCCC1</smiles>

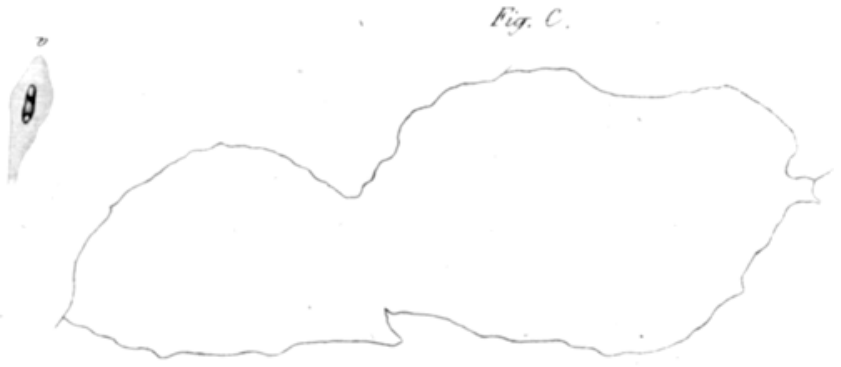


reichern, lässt allerdings an Bequemlichkeit Nichts zu wünschen übrig und kann nach Bedarf noch weiter mit Erfolg fortgesetzt werden; nur wird man sich dabei freilich darauf gefasst machen müssen, dass diese oder jene Krankheitsform früher oder später ihre Geltung verliert und ausser Cours gesetzt wird.

Eine noch grössere Mannichfaltigkeit lässt sich weiterhin noch dadurch erzielen, dass man nicht allein die nach dem Inhalte des Wahns aufgenommenen Krankheitsbilder zu besonderen selbstständigen Krankheitsformen erhebt, sondern auch noch Krankheiten der einzelnen Seelenvermögen *) statuirt **). Auch hier liegt noch ein reiches, nicht weniger bequemes Feld offen. Man könnte auf diese Weise Krankheiten der Einbildungskraft, des Scharfsinnes, des mathematischen Verstandes, des Witzes, der Weisheit, der Logik u. s. w. statuiren $* *$ ). $O b$ es aber eine richtige

*) Es verdient angemerkt zu werden, dass die „Vermögen der Seele“, die wir durch die neuere Philosophie als gesonderte selbstständige Wesenheiten aus dem Reiche der Lebendigen längst ausgemerzt und in die Schranken der formalen Logik zurückgewiesen glaubten, neuerdings anf dem Gebiete der Patbologie wieder als selbstständige Wesenheiten behandelt werden.

**) z. B. „Erkranken der Besonnenheit, Krankheiten der Kritik“. S. Ne u ma nn's Lehrb. d. Psychiatr. 18j9. S. 110 u. 111.

***) Nur vom Standpunkte Gall's könnte man eine solche Eintheilung der Geisteskrankheiten nach den einzelnen Vermögen gelten lassen; aber auch bier würde es sich doch immer nur um, Erkrankungen der (27 oder mebr) speciellen Hirn-0rgane handeln, nicht um Erkrankung der psychischen Elementarkräfte. Der Begriff Krankheit betrift das Organ, die Störung die Func: tion. Wir reden dessbalb von Krankbeiten der Organe und Organtheile und von Störungen der Functionen. Indem der Begriff larankheit sich auf das lebendige Organ bezieht, ist darin einerseits die anatomische und chemische Veränderung (Abweichungen in der Mischung und Form) andererseits die Störung der Function mit einbegriffen. - Wenn wir von Geisteskrankheiten sprechen, so verstehen wir darunter diejenigen Krankheiten des menschlichen Organismus, deren wesentlichste symptome in längere Zeit dauernden Störungen der geistigen Functionen bestehen. Es ist leicht ersichtlich, dass die für die Geisteskrankheiten vorgeschlagene Bezeichnung "Geistesstörung" den Begriff dessen, was wir unter Geisteskrankheit verstehen, nicht vollständig wiedergibt, weil in dieser Bezeichnung nur die functionelle Seite des Krankheitsprozesses Berücksichtigung findet, Da es sich aber für den Arzt picht bloss ụm die Störung der Func- 
Logik ist, die Logik selbst erkranken zu lassen, diese Frage zu beantworten darf ich wohl der gesunden Logik des Lesers anheimgeben, ohne hier weiter eine Kritik der erkrankten Kritik unternehmen zu müssen, und ich will desshalb auch nicht bei der Perspective verweilen, die sich uns durch die Combination der beiden genannten Methoden etwa eröffnen möchte.

Den psychischen Defect- und Schwächezuständen ist eine solche eingehende Specialisirung nicht zu Theil geworden, da sie wegen der Oede und Leere des Geisteslebens kein so bequemes und fassliches Material für die Construction von neuen Krankheitsspecies darbieten. Während bei dem Wahnsinnigen oft ein completes System, ein zusammenhängendes Gewebe von Wahnvorstellungen, gleichsam fertige Gebäude gefunden werden, denen man bloss einen Namen zu geben braucht, um eine neue Krankheitsform zu haben, so bietet uns der Blödsinn häufig nichts weiter als öde Fragmente, als Trümmer und Schutt, als auseinandergefallene und nach Zufälligkeit durcheinander gewürfelte Bröckel der früher im Bewusstsein thätig und wirksam gewesenen Vorstellungskreise.

So hat man sich denn im Allgemeinen damit begnügt, sämmtliche psychische Defect- und Schwächezustände in eine gemeinschaftliche grosse Rumpelkammer unter der Bezeichnung Blödsinn zusammenzuwerfen, und hat die einzelnen Fälle nur nach dem Grade, nach der Zeit ihrer Entstehung (congenitaler, erworbener, seniler Blödsinn), ferner nach ihrem Auftreten in Bezug auf andere Geisteskrankheiten (primärer und secundärer Blödsinn), sowie endlich, je nachdem sie mit oder ohne Aufregung bestehen (Verwirtheit und apathischer Blödsinn) unterschieden.

Wenn wir nun aber die Einzelfälle der Geistesstörungen einer genauen Untersuchung auf dem sicheren (freilich hier noch nicht völlig approfondirten) Boden der pathologischen Anatomie und einer eingehenden klinischen Prüfung unterwerfen, so gelangên wir, im Gegensatze zu dem besprochenen Eintheilungsverfahren, zu dem

tion, sondern hauptsächlich um den Krankheitsprozess handelt, so dürfte es zweckmässig sein, die einmal vorbandene und gebräuchliche Bezeichnung Geisteskrankheit oder psychische Krankheit festzuhalten. 
Resultate, dass viele der als besondere Krankheiten betrachteten Formen von Wahnsinn und Manie nur durch unwesentliche und zufällige Eigenthümlichkeiten und Beziehungen von einander verschieden sind und sich nicht als besondere Krankheiten aufrecht erhalten lassen, vielmehr blosse Varietäten darstellen; - dass hingegen die Kategorie Blödsinn ganz wesentlich ron einander differente Zustände in sich begreift und in besondere Krankheitsprozesse oder Zustände aufgelöst werden múss, - in analoger Weise wie der Begriff "Blindheit" nicht einem bestimmten Krankheitszustande entspricht, sondern wesentlich verschiedene Krankheitszustände umfasst.

Am frühesten hat man sich genöthigt gesehen, die Idiotie von dem Blödsinn zu trennen. Hierzu musste schon die Erwägung führen, dass wo das Seelenleben überhaupt nicht zur Entfaltung gekommen, wo die geistige Entwickelung gar nicht bis zu logischen Denkoperationen gediehen und kein Vorrath von Begriffsund Gedankenreihen elworben ist, dass da auch keine Fragmente eines früheren geistigen Erwerbes vorhanden sein können wie beim erworbenen Blödsinn und dass demnach auch die Qualität der psychischen Vorgänge bei beiden Formen präsumtiv verschieden sein muss. Durch den Nachweis verschiedener Hirn- und Schädelfehler*) hat sich dann diese Abtrennung noch mekr befestigt.

Ebenso hat man sich allmälig daran gewöhnt, den senilen Blödsinn apart $\mathrm{zu}$ betrachten und den Greisenkrankheiten arzureihen. Eine andere Gruppe ist durch die "Complication" mit Paralyse unter dem Namen Dementia paralytica zu einer gewissen Sonderstellung gelangt, obne dass man aber im Uebrigen über die Besonderheiten und den principiellen Unterschied derselben von anderen Formen völlig klar geworden, wäre.

Und doch bieten die verschiedenen Gruppen von Blödsinns-

*) Ich selbst habe erst vor Kurzem in einem Falle von Idiotie und Epilepsie eine interessante Structur-Anomalie des grossen Gehirns gefunden, die durch vielfache sphäroide Einlagerungen grauer Hirnsubstanz in die Marklager der grossen Hemisphären, zumeist in der Nähe der Corticalsubstanz, bedingt war. S. Allg. Zeitschrift für Psychiatrie, Bd. XXI. S. 48I. 
formen ganz wesentliche Differenzen dar, sowohl in ihrer anatomischen Grundlage als auch in Bezug auf die Modification der seelischen Prozesse.

Die pathologisch-anatomischen Veränderungen aber bilden nebst der Krankheitsgenesis die sichersten Grundlagen für eine wissenschaftliche Bearbeitung und Classification der Geisteskrankheiten. Es soll damit der Bestimmung des besonderen Inhalts und der Gestaltung des Krankheitsbildes durch besondere, ganze Symptomencomplexe zusammenfassende, Bezeichnungen ihre volle Berechtigung und Nützlichkeit für das praktische Bedürfniss keineswegs abgesprochen werden. Nur wird man sich stets bewusst bleiben müssen, dass wir die eigentliche Krankheit weder in den Ideenkreisen des Wahnsinns noch in den einzelnen Vermögen der Seele, sondern einzig und allein in dem beseelten menschlichen Organismus zu suchen baben. Durch eine genauere anatomische Untersuchung und durch Vergleichung der dadurch erhaltenen Resultate mit den Ergebnissen der psychologischen Analyse dürfen wir hoffen, eine grössere Bestimmtheit und ein besseres Verständniss für die den Geistesstörungen zu Grunde liegenden Prozesse zu gewinnen, als durch ein bloss summarisches Verfahren und durch eine unzulängliche und grobe.Statistik, wie sie bisher vielfach üblich gewesen ist und zu verfrübten Speculationen Veranlassung gegeben hat.

Ein Fall von Porencephalie, welchen ich bei einer epileptischen und zugleich halbseitig gelähmten Blödsinnigen beobachtete, bot mir Gelegenheit, die hier beobachtete Form des epileptischen Blödsinns - die man zur Unterscheidung von anderen Formen als porencephalischen Blödsinn bezeichnen mag - mit dem paralytischen Blödsinne zugleich vom anatomischen und klinischen Standpunkte einer vergleichenden Analyse zu unterziehen. Nach einer oberflächlichen Nomenclatur würde man beide Blödsinnsformen als mit unvollkommener Paralyse und mit Sprachbehinderung complicirte in dieselbe Kategorie bringen können, wie es denn auch in der That einzelne Autoren ( Lunier) geradezu ausgesprochen haben, dass die allgemeine fortschreitende Paralyse der Geisteskranken eine besonders nahe Beziehung oder 
Verwandtschaft zu der epileptischen Geistesstörung habe: eine Ansicht, die offenbar durch die in einzelnen Fällen von Epilepsie zu beobachtenden dauernden Motilitätsstörungen und Behinderungen, sowie durch die epileptiformen Anfälle der Paralytiker veranlasst worden ist, der ich aber nicht beitreten kann.

Der Fall von Porencephalie ist folgender:

Ottilie Lampert (H.-J. No. 85.), 27 Jahre alt, unverheirathet, am 5̆. Juli 1855 wegen Epilepsie und linksseitiger Hemiplegie in das Land-Krankenhaus zu Schwetz aufgenommen. Ein ärztliches Attest vom 30. Septbr. 1852 bekundet, dass die obere Extremität vollständig, die untere unvollbommen gelähmi sei und dass Epilepsie bestehe. Ueber die Krankheitsgenesis ist sonst nur ermittelt, dass die Lähmung aus früher Kindheit, die Epilepsie aus der Zeit der Pubertäts - Entwickelung datirt. Da sich bei der Pat. bald das Vorhandensein von Blödsinn herausstellte und häufige epileptische Zornwuth-Paroxysmen auftraten, so erfolgte am 7. Jan. 1856 die Aufnahme in die hiesige Irren-Anstalt.

Der Zustand, welchen Pat. während íhres 4-5jährigen Aufenthalts in letzterer dargeboten, ist in Kurzem folgender:

Wohlgenährter Körper, mittlere Grösse, blühende Gesichtsfarbe, freundlich belebter Gesichtsausdruck, mässig erweiterte Pupille, cyanotische Färbung der Extremitäten, namentlich der Hände, Behinderung der Sprache in der Weise, dass zuweilen der Redefluss vor einem Worte stockt und erst nach einiger Anstrengung wieder in Fluss kommt, unvollkommene Lähmung und geringe Atrophie des linken Arms mit Contractur des Handgelenks, dessgleichen Paresis des linken Beins mit Genu valgum und Plattfuss, sehr unbebülflicher Gang, Prolapsus ani, sehr seltene Menstruation; häufige epileptische Anfälle bei Tage und bei Nacht, bei deren Häufung zuweilen comatöse Zustände mit Flockenlesen, grösserer Unbesinnlichkeit, Gehörshallucinationen, hallucinatorischen Monologen und Secess. insciis. Die Anzah] der epileptischen Anfälle für die einzelnen Tage des Monats Juli 18ã7, sowie für diesen und für die folgenden Monate ist aus nachstehender Zusammenstellung ersichtlich, in welcher die Ziffern oberbalb der Linie die Tage und Monate bezeichnen, während die unter der Linie stehenden die Zahl der, in den entsprechenden Zeitabschnitten beohachteten, Insulte angeben.

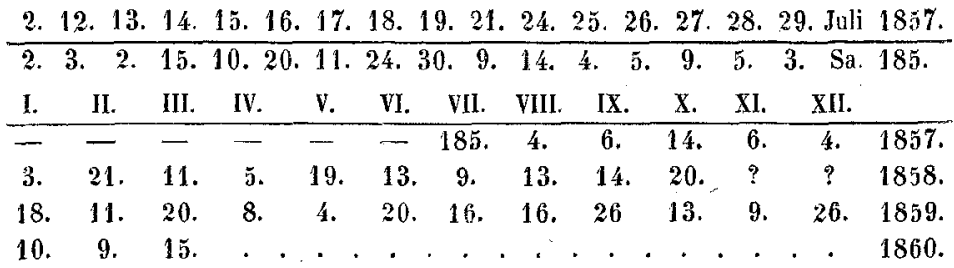

Der bestehende Blödsinn charakterisirte sich durch eine allgemeine Geistesschwăche, grosse Gedächtnissłücken, Gedächtnissschwäche, durch Mangel an Inter- 
esse für die Umgebung, für Gegenwart und Zukunft, durch eine mangelhafte Beobachtung der Verhältnisse und eine blödsinnige Ergebung in ein ganz müssiges Leben ohne Langeweile. Ueber ihre frïheren Lehensverhältnisse konnte Pat. nur äusserst spärliche Auskunft geben, irrte sich leicht in der Jahreszabl, pllegte in der Regel nur auf einfachere, ihr Befinden u. dgl. betreffende Fragen genügende und klare Antworten zu geben. Im Uebrigen waren die intellectuellen Fähigkeiten in ihren elementaren Formen, so za sagen in ihrer elementaren Technik der Hauptsache nach ziemlich gut erhalten; denn Pat. zeigte noch für einfache Verhältnisse Sinn und Verständniss, erschien im Kopfrechnen bei leichten Aufgaben ziemlich sicher und pflegte Fehler, welche andere Geisteskranke bei einfachen Zahlenoperationen machten, ohne Schwierigkeit zu entdecken. Auch waren bei ihr noch Fragmente guter Schulkenntnisse vorhanden, woraus zu sclbliessen, dass Pat. nicht ohne Anlagen gewesen ist. Abgesehen von den mit epileptischen Insulten einhergehenden Paroxysmen völliger Geistesabwesenheit war keine eigentliche Verwirrtheit vorhanden, keine Verkehrtheit des Urtheils, keine auffallende Incohärenz und Verfälschung der Gedankenreihen durch Wahn-Ideen oder Hallucinationen. Vielmehr war in den Denkoperationen noch ein gewisser Zusammenhang und eine gesetzmässige, wenn auch sehr träge Association der Vorstellungen zu erkennen. Pat. hatte im Allgemeinen ein richtiges Bewusstsein ihrer Lage, ihrer Lähmung und ihres geistesschwachen Zustandes and war in einer gewissen Beschränkung noch im Stande, die causalen, zeitlichen und räumlichen Beziehnngen der Dinge und Ereignisse, der Wirklichlieit entsprechend, aufzufassen. Aber der geistige Horizont war verengt, das geistige Gesichtsfeld wie durch einen Nebel getrübt, zum Theil freilich auch ganz verdunkelt, nur ein enger Kreis genügend klar erhellt. Das Vorstellungsleben war, was die Geschwindigkeit und die Intensität des Vorstellungsflusses betrifft, erheblich gesunken. Es waren nur wenige Vorstellungen im Bewusstsein thätig und nur ein geringer Vorrath im Gedächtnissschatze vorbanden und erregbar und diese selbst, wie gesagt, von langsamerer Bewegung und geringerer Intensilät. In der Sphäre des Gemüths und Willens war gleichfalls eine allgemeine Schwäche und Abstumpfung vorhanden und auch hier wurden, von intercurrenter epileptischer Zornwuth abgesehen, tiefere Perversionen vermisst. Vollkommene Apathie war indess nicht vorhanden.

So wenig auf somatischem als auf psychischem Gebiete machten sich im weiteren Verlaufe bis April 1860 erwähnenswerthe Veränderungen bemerklich. Die epileptischen Anfälle pflegten ohne Aura ganz plötzlich einzutreten. Pat. war desshalb zum Schutze ihres Kopfes mit einer gepolsterten Kopfbinde, einem sogenannten Fallkranze, den sie beständig trug und durch welchen insbesondere die der vorbandenen Knochenlüclse im Schädeldach entsprechende Gegend des Koples bedeckt wurde, versehen. Im April traten am 3.-6. (incl.) täglich 2 Anfälle, am 8. und 9. je ein Insult auf. Während von dieser Zeit an keine epileptischen Krampfanfälle beobachtet wurden, konnte man eine Verschlechterung des Allgemeinbefindens constatiren: es steIlten şch atonische wässerige Diarrböen, Oedema pedum und sonstige Zeichen eines tuberculösen Leidens ein. In der Nacht rom 16. zum 17. April heftiger Fieberfrost, Cephalalgia, demnächst Benommenheit des Sensoriums, 
excessive Reizbarkeit des Gemütbs, trockene brennende Hitze, Coma und unter Zunahme dieser Erscheinungen schneller Coliapsus und Tod Nacbts 12 Uhr.

A utopsie 36 h. p. m. Normale Körperfülle, mässig starkes Fettpolster. Bauch aufgetrieben. Bauchdecken grünlich gefärbt. An der Dorsalseite Todtenflecke, am Rücken einige Fäulniśsblasen. Ausserdem die schon im Stat. pr. aufgeführten Veränderungen der linksseitigen Gliedmaassen.

Bauchhöble: In cavo peritonei seröse Flüssigkeit in mässiger Quantităt. Kleine, blutarme, etwas fettige leber. Ungewöhnlich lange Gallenblase, enthaltend ร grüne Gallensteine von Wallnuss- (2) und Haselnussgrösse (3) und mit grüngelhen Flocken untermischte Galle. Mässig vergrösserte und erweichte Milz. Nierenhyperämie. Magen und Darm nicht abnorm. Anteflexio uteri măssigen Grades; in cavo uteri eine kleine polypöse Schleimhautwucherung. Grosse normale Ovarien.

Brusthöhle: Alte pleurale Adhäsionen. Hyperämie, Oedem und Tuberculose beider Lungen. In beiden Lungen mehrere bohnengrosse, auf dem Durchschnitte homogen und weissgelb erscheinende Knoten; ausserdem lobulär begrenzte durch Anhäufung vieler kleiner Knötchen und Körnchen entstandene knotige Verhärtungen; in beiden Spitzen haselnussgrosse cavernöse Erweiçhungsherde. Verbältnissmässig etwas grosses Herz, schlaffe, hie und da leicht gelblich schimmernde Muskulatur.

Schädeltöhle: Im rechten Seitenwandbeine befindet sich etwa $1 \frac{1}{2}$ Zoll (Rheinl.) hinter der Kronennaht eine 3 Zoll lange, $\frac{1}{2}-1$ Zoll breite Oeffnung, welche rechts von der Pfeilnaht und derselhen ziemlich nahe beginnend, parallel der Kronennaht quer nach rechts verläuft. Dieselbe ist durch eine an Stelle des defecten Knochenstücks getretene fibröse Membran geschlossen. Nachdem man nach Ablösung der behaarten Kopfhaut diese Membran durch einen Kreuzschnitt getrennt und die Hautlappen zurückgeschlagen bat, sieht man unmittelbar in eine mit heller wasserklarer Flüssigkeit gefüllte, etwa faustgrosse über 2 Zoll tiefe Höble. Dieselbe ist 3 Zoll lang, $2 \frac{1}{4}$ Zoll breit, $2 \frac{1}{2}$ Zoll tief und nimmt fast die ganze hintere Hâlfte (etwa $\frac{3}{7}$ der Länge) der rechten Hemisphäre des grossen Gehirns ein. Auf ihrem etwas bügeligen Grunde sieht man vorn einen Theil des Ammonshorns, bedeckt vom Plex. chorioid, mitten und hinten weisse Hirnsubstanz, welche in der Mittellinie einen vom Ammonshorn nach binten sich ziehenden, und unter sanfter Erhebung in die Medullarsubstanz des hinteren Lappens sich verlierenden Wulst bildet und an ihrer Oberfäche einige Gefässverzweigungen deutlich erkennen lässt.

Eine genauere Untersuchung ergibt Folgendes: Länge der linken Hemisphäre (gemessen nachdem das Gehirn aus dem Cranium herausgenommen) $8 \mathrm{Zoll}$, diejenige der rechten 7 Zoll, Von den zwei Theilen, in welche die rechte Hemisphäre durch die Höhle geschieden wird, ist der vordere Theil (von der vorderen Höblenwand bis zur Spitze des Stimlappens gemessen) 4 Zoll lang; der hintere Theil (von der hinteren Höblenwand bis zur Spitze des binteren Lappens gemessen) 1 Zoll lang, $1 \frac{1}{4}$ Zoll hoch und beinabe 2 Zoll breit. Die vordere Wand der Höhlung stellt eine ziemlich verticale, zur borizontalen Grundfläche rechtwinklich 
aufsteigende Ebene dar, die bintere Wand wird durch die allmälig sich erhebende Grundfläche gebildet und stösst mit der oberen in einem spitzen Winkel zusammen. Die der äusseren und inneren Oberfläche der Hemispbäre enisprechenden Seitenwände bestehen aus einer durchschnittlich $2-1$ Linien dicken Schicht des übriggebliebenen corticalen Theils der Hemisphäre, welche sich von unten nach oben zusehends verdünnt, allmälig in weiches, zartes, fast gallertartig durchscheinendes Gewebe von $1-\frac{1}{4}$ Linien Dicke übergeht und sich in die obere Wand verliert. Diese letztere besteht lediglich aus der erwähnten fibrösen, die Knochenlücke schliessenden Bindegewebshaut und einer an deren Innenseite dicht anliegenden, sehr dünnen, zarten, gallertig durehscheinenden Membran. Die oberste, der Pia mater und Arachnoidea entsprechende Schicht der äusseren Seitenwand entbält ringsum in der Nähe der Knochenlücke mehrere verkalkte Stellen in Form dünner Plättchen und diffuser Trübungen.

Die 0 berfläche des von der erwähnten 0effnung aus sichtbaren Theils des Ammonshorns und des beschriebenen Wulstes ist mit einem sebr verdickten Ependym bedeckt und mit bellen klaren Ependymgranulationen von der bekannten Beschaffenheit besetzt. Letztere sind von ungewöhnlicher Grösse. Sie erreichen den Umfang der gewöhnlichen Stecknadelköpfe. Eine bemerkenswerthe Pigmentirung ist an der Innenwand der Höhle mit blossem Auge nicht wahrzunehmen.

Die im Allgemeinen normal dicke und glatte Dura mater ist am Bande der mit einigen Osteophyten und Knochenwucherungen ringsum besetzten Knochenlüclse mit dem Cranium verwachsen und verliert sich bier in die beschriebene, die Lücke schliessende fibröse. Haut.

Der Sinus und Sulcus transversus ist rechts stark, links sehr schwach ausgebildet.

Die A rachnoidea im Allgemeinen normal, nicht ödematös oder verdickt, zeigt nur hie und da milchige Trübungen.

Die Pia mater blutreich mit diffus ekchymotischer Färbung in den Sulcis, besonders rechts (Leichenphänomen?), lässt sich von der Oberfläche beider Hemisphären glatt abheben.

Beide weichen Häute gehen oben und zum Theil auch in der mittleren Partie der änsseren Seitenwand, ihre charakteristische Structur verlierend, in das aben beschriebene zarte weiche, leicht zerreissliche, blassfleischröthliche, homogengallertig durchscheinende nembranöse Gewebe über, welches an der inneren Seite der fibrösen Membran anliegt und, wie schon erwähnt, hauptsächlich die obere and den oberen mittleren Theil der Seitenwandung bildet. Die innerste Lage der letzteren geht allmälig und obne scharfe Grenze in das Ependym der Ventrikel über.

Die Substanz der grossen Hemisphären erscheint im Allgemeinen normal, mässig feucht, von guter, links etwas weicher Consistenz. Die graue Substanz erscheint rein, klar, nicht getrübt. Die Färbung derselben fällt im Allgemeinen, insbesondere gegenüber der schmutzig gelblich aussebenden Corticalis einer zu glejcher Zeit secirten Leiche eines paralytischen Blödsinnigen (dessen Krankheitsgeschichte S. 276 u. ff, ausführlicher mitgetheilt ist) mehr in's Blaugrape und ist blass, 
Die Medullarsubstanz gleichfalls blass, anämisch, sonst ohne erkennbare Abnormitäten. Namentlich ist die der Höhlung angrenzende Partie der Hirnsubstanz im Wesentlichen von normaler Farbe und Consistenz, die Marksubstanz rein, weiss und consistent. Nur in der nächsten Umgebung der Höhlung scheint die Gefäsśentwickelung bedeutender zu sein.

Die Oberfläche des linken Corp. striat. ist mit der äusseren Ventrikelwand verklebt. Tiefer Türkensattel, normale Hypophysis.

Das Cerebellum kleiner als gewöhnlich. Rechte Hemisphäre kleiner als die linke; die ä ussere Hälfte atrophisch und verhärtet. Die Atrophie betrifft hauptsächlich die Corticalsubstanz, deren Dicke auf den vierten bis secbsten Theil der normalen reducirt ist. Aber auch die weisse Substanz zeigt Schrumpfung und insbesondere bedeutende Verhärtung. Die weichen Hänte lassen sich im ganzen Umfange des kleinen Gehirns von der Oberläche der Windungen glatt abheben.

Mikroskopiscbe Untersuchung.

Die Ependym-Granulationen bestehen aus vielen Kernen mit feinkörniger Zwischensubstanz. Das verdickte Ependym enthält Amyloidkörner. Jodschwefelsäure-Reaction: rothviolette, rundlich-ovale Körperchen. Die innere Auskleidung der oberen und der Seitenwände besteht aus zartem fibrillären, welligen Bindegewebe mit vielen gelbbraunen und rostfarbenen Pigmentanhäufungen, welche längliche, wellig gebogene und häufig sich gabelförmig (dichotomisch) theilende Zïge und eine Art durchbrochenen Netzwerks darstellend, stellenweise an Gefässverzweigungen erinnern. - In der rechten äusseren Seitenwand wird der Uebergang von der dünnen Lage Gebirnsubstanz zur weichen, leicht zerreisslichen Bindegewebsmembran durch ein etwas festeres, schwerer zerreissliches Gewebe gebildet, welches eine mittlere Lage darstellt und aus fibrillären Bindegewebszügen, fein granulären Massen, vielen Kernen und zah/reichen Gefässen besteht. In diesem leicht röthlich schimmernden Gewebe sind eine Menge kleiner, mit blossem Auge kaum erkennbarer, runder Concretionen eingesprengt, welche aus einer inneren, verschieden geformten, dunklen, auf der 0 berffäche drusig-höckerigen Centralmasse und einer blass-lehmfarbigen, manchmal concentrisch-geschichteten Umhüllangsmasse bestehen. Salzsäure löst die Centralmasse ohue Luftentwickelung vollständig auf. (Sie stimmen mit den in Virchow's Werke "Die kranklıaften Geschwülste“ II. S. 109 in Fig. 124 abgebildeten Sandkörpern vollständig überein.)

Die Nervenzellen der Hirnrinde erschienen nicht merklich verändert; im Allgemeinen verhältnissmässig etwas klein, mehr hell, etwas glänzend and obne bemerkenswerthe Einlagerung von Fett- und Pigmentkörnchen (s. Abbildung). Das Gefässsystem der Corticalsubstanz war, wie überbaupt im ganzen Gehirn, nur schwach entwickelt, das Capillargefässnetz sparsam, die Capillaren dünn, schmächtig, wenig mit Blutkörperchen angefiillt.

Vergleichen wir nun diesen Fall von epileptischem, beziehungsweise porencephalischem Blödsinn mit dem paralytischen Blödsinue zunächst in Bezug auf die beiden Formen zu 
Grunde liegenden anatomischen Veränderungen, so zeigt uns schon die beigefügte Abbildung der mikroskopischen Präparate, die aus correspondirenden und in gleicher Weise bebandelten Partieen der Corticalsubstanz des grossen Gehirns entnommen waren (s. Taf. I.), einen frappanten Unterschied. Während die Nervenzellen der Hirnrinde bei dem paralytischen Blödsinnigen (Fig. A und Fig. a bis u) sich im Zustande der fettigen Degeneration und Auflösung befinden, sieht man sie in dem Prầparate Fig. B und Fig. 1 bis 10 (dem eben mitgetheilten Falle von Porencephalie angehörend) fast ganz frei von Fettkörnchen und Pigmenteinlagerung, zugleich scluärfer contourirt, heller und soweit man nach dem Augenmaass urtheilen kann, auch im Ganzen klẹner. Die Vascularisation ist ausserdem viel dürftiger entwickelt. Wenn hier also noch eine gewisse Integrität der Nervenzellen vorhanden ist, die beim paralytischen Blödsinn fehlt', so haben wir hier aber einen grossen Defect ron Hirnsubstanz, einen Ausfall eines umfangreichen Bezirkes von Hirnwindungen und damit auch einen Defect von Tausenden von Nervenzellen, deren Zahl dagegen beim paralytischen Blödsinn unverkürzt ist. In dem einen. Falle sind also die einzelnen Componenten. in ihrer organischen Zusammensetzung alterirt, in dem anderen ist nur die Summe derselben verringert; hier handelt es sich hauptsächlich um die $Q$ uantität, dort um die Qualität der Nervenzellen des grossen Gehirns*).

Dieser anatomisch nachgewiesenen Differenz beider Fälle entspricht eine analoge Differenz des Blödsinns und der Lähmung.

Der blödsinnige Zustand der Lampert, wie wir inn in Vorstehendem nach mehrjähriger Beobachtung skizzirt haben, lässt sich hauptsächlich auf folgende Momente zurückführen:

1. Gedächtnissschwäche, insofern a) vieles früher in der Erinnerung vorhanden Gewesene vollständig vergessen ist; b) der noch vorhandene Gedächtniss-Inhalt nur langsam und un-

*) Eine Erörterung über die Bedeutung der Veränderung des kleinen Gehirns, über dessen Function wir haum Vermuthungen haben, sowie des Defects der-Medullarsubstanz, würde hier zu weit führen und die Grenzen dieser Arbeit zu sehr ausdehnen. 
deutlich erinnert wird; c) vieles Wahrgenommene uberhaupt nach kurzer Zeit wieder ganz vergessen wird.

2. Beschränktheit des geistigen Horizontes. Es sind weniger Vorstellungen im Bewusstsein thätig und in Folge von 1. auch weniger im ruhenden Zustande (virtuell) vorhanden.

3. Verminderung der Intensität der Vorstellungen. Dieselben sind gleichsam abgeblasst, treten weniger scharf ausgeprägt hervor (wesshalb leicht Irrthümer und Unklarheiten vorkommen), erregen weniger das Interesse und die Strebung, influiren weniger auf den Willen.

4. Verlangsamung der Bewegung der Vorstellungen, des Gedankenflusses: Trägheit der Auffassung, der Association und der Combination.

5. Hieraus resultirend: Unvermögen complicirtere Verhältnisse aufzufassen, zu beurtheilen, zu übersehen und zu abstrahiren. Simplicitas.

Dagegen gehen bei dieser Kranken die elementaren Operationen des Vorstellungslebens noch nach richtigen Normen von statten und geben dem ganzen Bewusstseinsleben noch einen gewissen Zusammenhalt, eine gewisse Festigkeit und Zuverlässigkeit. Die einzelnen Vorstellungen, welche durch die äusseren Wahrnehmungen entstehen oder aus dem Gedächtnisse wieder bewusst werden, baben im Allgemeinen ibre Identität und die Bestimmtheit ihres Gep räges unverfälscht erhalten, ebenso ihre richtigen Beziehungen, wenn auch in unvollständiger Weise, und associiren sich im Allgemeinen noch gesetzmässig. Die aus dem Gedächtniss wieder in's Bewusstsein getretenen Vorstellungen haben im Grossen und Gapzen ihre bestimmte Stellung zu einander und in dem grossen Rahmen der Zeit- und Raum-Anschauung, - und die aus der äusseren Wahrnehmung entnommenen entsprechen der Hauptsache nach der Wirklichkeit. Die Vorstellungsbilder beider Kategorieen, wie abgeblasst, getrübt, verwischt, verdunkelt, und wie wenig zablreich und nachhaltig sie auch sein mögen, sind doch, soweit sie noch sichtbar sind, der objectiven Wirklichkejt conform und von richtigem Ebenmaass. Die allgemeine Zeit- und Raum-Anschauung ist dem Bewusstsein noch unverzerrt (wenn auch nicht mit detaillirter 
Genauigkeit, Sicherheit und Ausdehnung) in den Hauptzügen gegenwärtig und dient den Anschauungen zur ordnenden Grundlage. Pat. ist desshalb im Stande, sich in der Zeit und in den räumlichen Verhältnissen und über ihre Lage zu orientiren.

Sie übersieht allerdings nun sehr wenig und wie durch einen leichten Nebel; aber was in den engen, lichtschwachen Focus des Bewusstseins fällt, das ist ein, wenn auch nicht immer ganz genaues, vollständiges und scharfes, doch im Wesentlichen ein treues, ein der objectiven Wirklichkeit adäquates Bild, ohne subjective Beimischung und Zuthat. Und diese Bilder werden noch unverfälscht fixirt, für das Gedächtniss „,verinnert“, können mit anderen richtig combinirt und zusammengefasst werden, wenn sie einfächer und übersichllicher Natur sind, während allerdings bei etwas complicirteren Verhältnissen die Uebersicht und damit das Begreifen und das Verständniss aufhört und Verwirrung und Incohärenz eintritt. -

Bei dem paralytischen Blödsinn dagegen finden wir eine Zerrüttung der elementaren Grundlagen der Denkoperationen.

Das gesammte Vorstellungsleben trägt den Cbarakter der Lockerung und fortschreitenden Auflösung.

In den äussersten Graden finden wir das Vorstellungsleben nahezu nullificirt, auf einige wenige zählbare incohärente Vorstellungen reducirt, das Gedächtniss vollständig erloschen, das Bewusstsein in tiefes Dunkel gehüllt. Es herrscht auf psychischem Gebiete die vollendetste Oede und Leere und zuweilen auch der höchste Grad von Apathie.

Diese Zustände der vollendeten Zersetzung und Auflösung bieten keine Anbaltspunkte, kein Material, um die charakteristischen Eigenthümlichkeiten des paralytischen Blödsinns zu studiren und wir haben sie nur als die End-Zustände, zu welchen der paralytische Prozess lendirt, festzuhalten.

Der Hauptsache nach müssen wir uns vielmehr an die mittleren Grade und an die früheren Stadien des Blödsinns halten, weil uns diese noch einen tieferen Einblick in das Getriebe des Vorstellungslebens gestatten. 
Beobachtet man nun eine Reihe recht typischer Fälle von paralytischem Blödsinn, so findet man, dass nicht allein grosse Massen des Gedächtniss - Inhalts für die Erinnerung vollständig geschwunden sind und dass die Wirklichkeit mangelbaft beobachtet wird, - sondern dass auch die zum Bewusstsein erregten Vorstellungen (seien sie nun aus dem Gedächtnisse oder aus der äusseren Wahrnehmung entnommen) in ihren wesentlichen Grundlagen und Beziehungen verändert sind, dass dieselben ihre Bestimmtheit in Bezug auf die primitiven Anschauungsformen eingebüsst haben, dass sie nach Quantität und Qualität eine subjective Umänderung erfahren und so umgestaltet in's Bewusstsein treten.

Es wird daher nicht allein mangelhaft erinnert und beobachtet, sondern geradezu falsch erinnert und falsch beobachtet. Das Denkgesetz der Identität hat aufgehört bindend zu sein. Die Vorstellungen und Begriffe sondern sich nicht, verschmelzen vielmehr unter einander und durchdringen sich gleichsam. Sie erscheinen gleichsam in einer veränderten Beleuchtung und Färbung, in anderen Dimensionen und Formen, in verschiedenen Bedeutungen und Beziehungen. Die Grössen, mit denen der Paralytisch-Blödsinnige rechnet, sind variable, verändern sich von einem zum andern Augenblick, wie man z. B. daraus sieht, dass er alle Fragen über die Höhe seines Vermögens, die man ihm suggestiv proponirt, bejahend und fortwährend variirend beantwortet und beliebig grosse und immer grössere Zahlen angiebt.

Dadurch wird das gesammte bewusste Geistesleben illusorisch. Es hängt das allerdings mit dem "Wahnsinn" zusammen. Alles geht in die Persönlichkeit des Kranken auf nach der Grundformel: Ich $=$ All $*$ ). Aber eben dieses allgemeine Aufgehen aller Sonderbegriffe, dieses Verschwimmen und Ineinanderlaufen aller Grenzen ist für den paralytischen Grössenwahn charakteristisch, nicht der exaltative Charakter des Wahns im Allgemeinen, der sich durch Ver-

*) Beispiel: Ein Kranker, Namens Peters, änsserte sich wie folgt: „Alle Menschen sind Peters, heissen allesammt Peters, ihr Alle heisst Peters, es gieht nur Peters, ich bin doppelt Peters; die ganze Welt gehört mir u. s. w." 
grösserung und Erhebung der Persönlichkeit documentirt und in vielen anderen nicht paralytischen Wahnsinnsformea vorkommt.

Je stärker dieser Charakter des Mass- und Grenzlosen in der Gestaltung der Wahnbilder hervortritt, desto mehr tritt das Element des Blödsinns in den Vordergrund.

Es erscheint mir eine ziemlich müssige oder wenigstens nicht ganz richtig gestellte Frage, ob diese Zerrüttung, Verschiebung und Lockerung der gesammten Anschauung "Folge" des Grössenwahns sei oder ob umgekehrt der Grössenwahn "Folge" des Blödsinns, "Folge ${ }^{66}$ der intellectuellen Lähmung sei. Das Richtige ist meines Erachtens, dass der paralytische Grössenwahn schon Elemente des Blödsinns und der paralytische Blödsinn in der Regel noch oder gleichzeitig Elemente đes Wahns enthält.

Beiderlei Kategorieen von Störung des intellectuellen Lebens sind Symptome des organischen Destructionsprozesses.

Die eine tritt vorzugsweise im Anfange, die andere am Ende ausgeprägt hervor; die eine giebt den früheren, die andere den späteren Stadien den Namen; aber in der Regel sind beide im ganzen Verlaufe der Krankheit nachzuweisen. Die eine Kategorie ist Symptom des Prozesses, die andere Symptom des Produkts, des durch diesen Prozess herbeigeführten Defect- und Schwächezustandes.

Wir sehen zuweilen schon sehr frühzeitig and als erstes auffallendes Symptom den intellectuellen Defect in den Vordergrund treten, und andererseits noch im Final-Stadium ausgeprägten Grössenwahn. Es sind diese Verschiedenheiten durch die verschiedene Gestaltung des organischen Prozesses bedingt.

Je activer sich der Prozess gestaltet und je widerstands. fähiger sich das Organ verhält, desto mehr prävaliren die Symptome des Deliriums und der Tobsucht; je träger und schleichender die Desorganisation sich vollzieht und je leichter das Organ zerfällt, desto mehr tritt der Blödsinn unverschleiert durch active Erscheinungen zu Tage.

Betrachten wir specieller das Verhalten des Gedächtnisses.

Der Inhalt unseres Gedächtnisses ordnet sich nach den Bestimmungen der primitiven Anschauungsformen, der Zeit 
und des Raumes. Zeit und Raum bilden gleichsam den grossen Rahmen, das Gerüst für unsere Erinnerungen, indem sich alle unsere Erlebnisse an einen bestimmten Raum und eine bestimmte Zeit knüpfen. Betrachten wir nun den Inhalt unseres Gedächtnisses, absebend von complicirteren Denkresultaten, in seinen einfachsten Elementen und Grundlagen, mit vorzugsweiser Berücksichtigung des durch den Gesichtssinn Wahrgenommenen, so können wir uns den Gesammtinhalt gleichsam aus einer grossen Zahl von Bildern, Tableau's, zusammengesetzt denken, von denen immer je eines einem Momente des wachenden Lebens entspricht und eine bestimmte Stelle in der Zeit (die wir uns unter dem Bilde einer Linie vorstellen können) einnimmt. So schiebt sich ein Bild vor das andere, ohne das frühere ganz zu verdunkeln, indem die oft wiederholten Theile sich stärker ausprägen und zugleich auch gewisse Bilder in ihrer Gesammtheit auffallend stark hervortreten. Durch letztere markiren sich gewisse Punkte und Abschnitte schärfer für unsere Erinnerung. Je bestimmter nun die Ausdehnung und Stellung der erinnerten Vorstellungsbilder in Bezug auf Zeit und Raum erkannt wird, um so schärfer, klarer und getreuer ist das Gedächtniss und je mehr und je grössere Bilder aus der Vergangenheit für das Bewusstsein erregbar geblieben sind, desto umfangreicher und reichhaltiger ist dasselbe. - Wenn wir uns nun an Etwas aus dem vergangenen Leben erinnern, so tritt nicht blos die betreffende Vorstellung isolirt in's Bewusstsein, sondern zugleich die Bestimmung der zeillichen und räumlichen Stellung und Ausdehnung und damit die Beziehung zu anderen Vorstellungen. Diese Bestimmungen der erinnerten Vorstellungen, insbesondere die Stellung derselben im Raume und in der Zeit, sind dem Bewusstsein immer gegenwärtig oder disponibel, werden in grösserer oder geringerer Ausdehnung und Stärke sofort mitbewusst.

Bei dem Paralytisch-Blödsinnigen haben die erinnerten Vorstellungen diese ihre räumliche und zeitliche Bestimmtheit grösstentheils verloren. Es fehlt für die Erinnerung das allgemeine, aus der Zeit- und Raum-Anschaunng combinirte, feste Gerüst, indem sich die einzelnen Tableau's in Bezug auf Zeit und 
Raum verschoben haben und demgemäss Vergangenes in die Gegenwart und Gegenwärtiges oder jüngst Vergangenes in eine ferner liegende Vergangenheit verlegt wird.

Dem Paralytisch-Blödsinnigen ist alles Maass für die Ausdehnung und alles Urtheil uber die Stellung, welche die Vorstellungen im Raume und in der Zeit einnehmen, verloren gegangen. In seiner Anschauung schrumpfen Jabre zu Tagen zusammen und dehnen sich Tage zu Jahren aus, das Heute wird Gestern, der Morgen Abend, der Nachmittag Vormittag. Er nennt sich den Ewigen, hat schon Tausende ron Jahren durchlebt. Für jhn gibt es weder Schranken der Zeit noch des Raumes. Seine 60 Jahre, die bereits sein Haar schneeweiss gebleicht haben, kommen ihm wie ein kurzes Knaben-Alter vor und er hält sich allen Ernstes für einen 18jährigen Jüngling. Er erzählt von Zeiten, die er nie erlebt hat und nur aus der Geschichte kennt und schildert Orte, die er nie gesehen hat. Es ist gar nicht selten, solche Kranken auch von ihrem gegenwärtigen Aufenthalte in der Anstalt wie von einem zum zweiten Male wiederholten sprechen und sie versichern zu hören, dass sie vor einigen Jahren sich schon einmal in derselben eine längere Zeit aufgehalten hätten.

Ebenso werden die Bilder der Zukunft in die Gegenwart oder in die Vergangenheit verlegt, $d . b$. sie treten in's Bewusstsein mit der Kraft und dem Gepräge der gegenwärtigen und vergangenen und werden als solche, wirliliche, anerkannt. Im normalen Vorstellungsleben nehmen die Vorstellungen der Zukunft (die Erwartungen, Hoffnungen, Wünsche, Projecte) iłıre bestimmte Stellung in der Zukunft (auf der über die Gegenwart hinaus verlängerten, projicirten Linie der Zeit) ein, treten in's Bewusstsein mit dieser besonderen Bestimmung als projectirte $u$. s. w. und werden desshalb eben auch als solche von den der gegenwärtigen Wirklichkeit angehörenden Vorstellungen unterschieden.' Bei dem Paralytisch-Blödsinnigen baben diese Vorstellungen (Projecte u. s. w.) die Bestimmung der Zeit rerloren. Damit ist der principielle Unterschied zwischen ihnen und den Vorstellungen der vergangenen und gegenwärtigen Wirklichkeit fortgefallen. Sie haben daher für ihn die Bedeutung der Wirklichkeit. Sobald sich 
bei ihm ein Wunsch regt, oder ein Project aufsteigt, wird die entsprechende Vorstellung, entkleidet von der beschränkenden Zeit- und Raumbestimmung, im Bewusstsein wirksam, gestaltet sich als Wirklichkeit*).

Auch den gegenwärtigen Wahrnehmungen dient eine allgemeine Raum- und Welt-Anschaung, die sich aus der Summe der einzelnen Tableau's, der einzelnen, im Laufe des Lebens sich uns einprägenden Vorstellungen construirt (innere Welt), zur ordnenden Grundlage. Sobald eine Wahrnehmung (resp. Vorstellung) in den Focus des Bewusstseins tritt, wird auch ein Theil dieser inneren Welt, in grösserer oder kleinerer Ausdehnung und in grösserer oder geringerer Lichtstärke mitbewusst, je nach dem Grade der Aufmerksamkeit und Besonnenheit. Die der einzelnen Wahrnehmung entsprechende Vorstellung hat gleichsam das concentrirteste Licht, während die Umgebung nur in ihren allgemeinsten Umrissen und in immer schwächerem Lichte erscheint und sich allmälig in Dunkelheit verliert. Durch den zugleich mit erleuchteten, zugleich mit in's Bewusstsein tretenden Hintergrund erhält das specielle Bild seine bestimmte Stellung in der inneren Welt. Dass uns in Wirklichkeit eine blasse Vorstellung von der ganzen Situation, in der wir uns befinden, immerfort begleitet, sehen wir am deutlichsten bei der sogenannten Zerstreutheit oder Vertiefung, die eben in einem Zurücktreten und Dunkelwerden der uns sonst immer begleitenden Raum- und Zeitvorstellung besteht. Man kann bei dem Uebergange aus solchem Zustande zu voller

*) Etwas Aehnliches findet im Traume statt. Auch hier werden die einzelnen Tableau's durcheinander gemischt, verschmelzen und combiniren sich zu sonderbaren Situationen und Gruppen, ohne Rücksicht auf Zeit und Ort. Einzelne Vorstellungen erscheinen isolirt, aus dem Gesammtbilde gelöst, wodurch die Continuität mit der dem wachenden Bewusstsein gegenwärtigen Anschauung unterbrochen ist. In einem analogen Zustande befindet sich der paralytische Geisteskranke. Zuweilen entwickeln sich Paroxysmen von heftigem GrössenDelirium in continuirlicher Weise direct aus wirklichen Träumen (vgl. die weiter oben mitgetheilten Fälle). In einem Falle erklärte der Kranke nach einem 30 Stunden lang andauernden Paroxysmus, sobald er wieder einigermaassen zur Besinnung gekommen war, selbst, er habe blos einen schweren Traum gehabt. 
Aufmerksamkeit ganz gut die temporäre Abwesenheit dieser sonst ununterbrochen vorhandenen Vorstellungen im Bewusstsein con= statiren. Wir können es ferner auch aus der eigenthümlichen Schwierigkeit uns zu orientiren, ersehen, die entsteht, wenn man zum ersten Male an einem anderen Orte oder in veränderter Stellung des Bettes schläft, die Veränderung aber im Schlafe vergessen hat und nun erwacht mit der alten, im Bewusstsein noch gegenwärtigen, bisher gültig gewesenen Raum-Vorstellung, wie sie sich durch die öftere Wiederholung befestigt hat. Jedermann weiss, dass zuweilen eine messbare Zeit, ein oder einige Secunden, dazu gehören, um sich zu ,orientiren", d. h. um die neue Raum-Anschauung zu bilden und zu fixiren. Ist dieses geschehen, so denkt man nicht mehr speciell an dieselbe, wiewohl sie uns gegenwärtig bleibt. Aehnlich verhält es sich mit der Zeit.

Bei dem Paralytisch-Blödsinnigen finden wir nun auch diese allgemeine Grundlage für die richtige Auffassung der Wirklichkeit schon frühzeitig erschüttert. Es ist ein charakteristisches Zeichen der an allgemeiner Paralyse leidenden Blödsinnigen, dass sie in Ort und Zeit auch für die Gegenwart ganz unorientirt sind. Ihr Zustand hat die grösste Aehnlichkeit mit den eben angeführten Zuständen der Zerstreutheit und der Schwierigkeit sich $z u$ orientiren beim Erwachen an einem fremden Orte. Es besteht nur der Unterschied, dass dort der Zustand vorübergehend, hier aber dauernd ist. Die im gesunden und wachenden Zustande dem Bewusstsein immer disponible, ,jeảen Winks gewärtige" Vorstellung der Gesammtsituation ist dem paralytischen Blödsinnigen abhanden gekommen.

Diese Unfähigkeit sich zu orientiren, über seinen Aufenthalt und über die Zeit klar zu werden, ist ihm häufig in's Gesicht geschrieben. Staunend und unstät starrt und stiert sein Blick umher, wie wenn er von Gestern wäre und die Welt zum ersten Male sähe, wie wenn er sich nicht zurecht finden könnte. Es spricht sich diese Störung des Orientirungsvermögens häufig genug auch in Handlungen und in charakteristischen Aeusserungen aus und wird nicht selten objectivirt, auf Andere übertragen. So erinnere ich mich eines Kranken dieser Kategorie, der 
aus seinem Fenster die vorübergehenden Leute betrachtend ängstlich sagte: „Da gehen nun die Leute hin und her, und Keiner weiss wohin; die rennen allesammt in eine Sackgasse; wie werden wir herauskommen? Ich glaube wir sind in der Unterwelt." Mit Recht hat schon Haslam unter den für die allgemeine Paralyse der Irren charakteristischen Symptomen auch aufgeführt, dass den Kranken das Bewusstsein ihrer Lage vollständig fehit.

Es fehlt ihnen die Continuität des Vorstellungslebens; sie haben in gewissem Sinne mit ihrem früheren Leben gebrochen. Schon im Beginne der Krankheit, im Stadium der Tobsucht und des Grössenwahns pflegt sich die Umgestaltung der inneren Welt (Welt-Anschauung) zu vollziehen. In der schon früher mitgetheilten in vollem Ernst und mit vollster Ueberzeugung gesprochenen Behauptung eines solchen Kranken *): „dass die Welt sich umgestalte und herangeflogen komme" spricht sich diese Veränderung der gesammten Welt-Anschauung und die verstärkte Bewegung auf dem Gebiete des Vorstellungslebens prägnant genug aus.

Die so umgestaltete innere Welt entspricht nicht mehr der Aussenwelt. Die Verhältnisse beider sind zum Theil incommensurabel geworden. Der Kranke rechnet hinfort mit anderen Formeln, mit imaginairen und variablen Grössen, bedient sich zuweilen neugebildeter Wörter, weil ihm die bisher üblichen unzulänglich erscheinen, (z. B. „Himalaya" für „,viel“).

Es gelangen also, wie wir geseben haben, sowohl die aus dem Gedächtnissinhalt, als die aus der äusseren Wahrnehmung kommenden und angeregten Vorstellungen, ihrer normalen Beștimmung entkleidet, in einer veränderten Form und mit veränderten Beziehungen in's Bewusstsein. Es ist wie wenn

*) Dieselbe wurde in den ersten Wochen der Krankheit beobachtet in einem Falle, der besonders desshalb instructiv war, weil er sehr frübzeitig zur Aufnahme in die hiesige Anstalt gelangte und gerade die seltener zur Beobachtung kommenden Erscheinungen des activen Anfangs-Stadiums in ausgeprägter Weise erkennen liess. Das erste beohachlete Symptom von Geistesstörung hatte in einer veränderten Auffassung der Situation überhaupt, sowie darin bestanden, dass Patient äusserte, die Personen, mit denen er kurz vorher verkehrt hatte, seien irre geworden und er babe deren Reden nicht verstehen können. 
das Organ des Vorstellens die in dasselbe gelangenden Bilder vergrösserte und umgestaltete und so verändert dem Bewusstsein zuführte, in den Focus des Bewusstseins projicirte; wie wenn sich der Brechungs-Index desselben verändert hätte.

Von dem Gẹdächtniss, insofern darunter die Fähigkeit verstanden wird, früher in das Gedächtniss aufgenommene Vorstellungen wieder in's Bewusstsein treten zu lassen (Erinnerungsvermögen) ist zu unterscheiden, die Fähigkeit, Vorstellungen (Wahrnehmungen) für eine spätere Erinnerung in sich, in den Gedächtnissschatz aufzunehmen (Verinnerung). Wie sehr diese Fähigkeit im paralytischen Blödsinne beeinträchtigt ist, habe ich schon früher erwähnt (s. meine Abhandlung „Die paralytische Geisteskrankheit und ihre organische Grundlage; S. 93 u. f.). Der Verlust dieses Vermögens manifestirt sich als „Vergesslichkeit". In Folge dessen ist der Kranke zu geistigem Erwerbe unfähig; er nimmt Nichts mehr dauernd in seine Erinnerung auf.

In den höheren Graden des geistigen Verfalls ist oft sogar auch die momentane Fixirung der einzelnen Bestandtheile der Wahrnehmungen und Vorstellungen unmöglich geworden. Die einzelnen Vorstellungen sind oft schon in der nächsten Secunde nicht mehr gegenwärtig, kommen dem Bewusstsein sofort wieder abhanden; selbst die einzelnen Theile entschwinden dem Bewusstsein, ehe das Ganze aufgefasst ist. In dieser Beziehung gleicht der Kranke einem Rechner, der auf einer Tafel Zahlen schreibt, auf welcher ihm die kaum niedergeschriebenen Ziffern unter der Hand verschwinden, ihre Form und Stellung ändern und sich schon während des Schreibens umgestalten.

Es giebt Fälle, in denen nicht einmal die Fähigkeit vorhanden ist, die einzelnen Buchstaben eines sonst ganz geläufigen Namens dauernd genug im Bewusstsein zu fixiren und in ihrem Ensemble im Bewusstsein aufzufassen. Es nennt z. B. ein Kranker die Buchstaben des Namens eines Freundes $B-r-a-n-d$ in richtiger Reihenfolge, aber er kann sich auf das ganze Wort nicht besinnen und dasselbe nieht aussprechen. Es ist diese besondere Manifestation der Vergesslichkeit ein interessantes psychologisches Phänomen, welches zeigt, dass das ganze Wort in richtiger und voll- 
ständiger Zusammensetzung im Gedächtniss enthalten ist, aber nicht in seiner Totalität zum Bewusstsein erregt werden kann, nicht auf einmal zur bewussten Anschauung gelangt. Die einzelnen Theile können nicht zu einem Gesammtbilde vereinigt, in ihrem Ensemble festgehalten und veräussert werden. Es ist, wie wenn das Gesammtbild, das Wort, durch einen Zerstreuungs-Apparat aufgelöst würde und die einzelnen Theile nur nacheinander, isolirt, vom Bewusstsein erleuchtet würden (wie wir beim Lesen durch ein Vergrösserungsglas in einer gewissen Entiernung auch nur jedesmal einen einzelnen Buchstaben eines Wortes wahrnehmen können).

Wie schon während des Niederschreibens die einzelnen Vorstellungen und Denkzeichen dem Bewusstsein entschwinden, zeigen uns die eigenthümliche Lückenhaftigkeit, die vielen Ellipsen und die orthographischen Fehler, die wir in den Schriftproben solcher Kranken finden, die früher durchaus correct schrieben.

Die abnorm articulirte, unverständliche Sprache der paralytischen Blödsinnigen, bei denen oft mehrere Buchstaben und Sylben wie zusammengekaut in einander fliessen, andere Theile der Rede sich ganz eklipsiren, wieder andere erst nach wiederholt genommenem Anlaufe flüssig werden, ist keineswegs, wie diess vielleicht scheinen könnte, blos Symptom der unvollkommenen Lähmung der beim Sprechen thätigen Muskeln*) (die Beeinträchtigung des Muskelgefühls und der Coordination mit einbegriffen), sondern zugleich auch durch das geistige Unvermögen bedingt. Einen schlagenden Beweis hierfür liefert uns das geschriebene Stottern, welches zuweilen bei diesen Kranken beobachtet wird. In solchen Schriftstücken ist der Einfluss der beiden Momente, der Lähmung der willkürlichen Bewegung und der Vergesslichkeit in schärfster Sonderung und mit photographischer Treue abgezeichnet. Die Motilitäts - Lähmung documentirt sich in den gèschlängelten und sägeförmigen Zickzacklinien der Buchstaben, die Vergesslichkeit in dem Auslassen und Wiederbolen ein-

*) Ueber die Bedeutung der Paresis der Kehllkopfmuskeln für die Veränderungen der Phonik in dem paralytischen Blödsinn und deren Nachweis durch Laryngoshopie vgl. Al. Schultz in d. Allg. Zeitschr. f. Psychiatrie, 1864. XXI. Bd. 5. u. 6. Hft, 
zelner Buchstaben und Sylben. Was in der Schrift für das Auge gesondert vorliegt, das verschmilzt beim sprechen für das ohr in Eins. Ein Fall, in dem ich in ausgeprägter Weise geschriebenes Stottern beobachtete, ist folgender.

5. Beobachtung. Paralytischer Blödsinn nach Ausschweifungen, andauernder Irritation and Depression des Gemüths. Grössenwabn schwach entwickelt. Paralytische Anfalle. Geschriebenes Stottern. - Adhärenz and Trübung der Hirnhäute. Degeneration der Nervenzellen des grossen Gehirns.

H.-J. No. 265, früher Gutshesitzer, von kräftiger und blühender Constitution, im Alter von 25 Jahren mit einer alten Wittwe verheirathet, nach vierjähriger unglücklicher und kinderloser Ehe geschieden, vom Gerichte für den schuldigen Tbeil erklärt. Ausschweifung und Verschwendung. Im Alter von 33 Jabren wegen Meineid zur Zuchthausstrafe verurtheilt. Während des circa $2 \frac{1}{2}$ jährigen Aufentbaltes im Gefängnisse allmälige Entwickelung der Krankheit. Abmagerung. Langsam fortschreitende allgemeine Paresis und Geistesschwäche. Remission nach der Entlassung im November 185\%. Besserer Ernährungs- und Kräftezustand. Bald daranf leichte Anfälle von Manie und Grössenwahn.

Bei der Aufnahme in die hiesige Anstalt am 7. October 1858 exquisites Bild des paralytischen Blödsinns: unvollkommen gelähmte stotternde Sprache, schwankender stolpriger Gang, Läbmung der Schliessmuskeln, Essgier, kindischgutmüthiges, zufriedenes willenloses Benehmen, anbaltend heiteres Lächeln, Zerrüttung der intellectuellen Fähigkeiten, insbesondere des Gedächtnisses und der Fassungskraft. Grössen-Ideen nur. wenig hervortretend. Am 6. December 1858 leichter paralytischer Anfall. Zu Anfang des Jahres 1861 leichte Fieberbewegungen; im April 1861 paralytische Schwindel-Anfälle, progressiv zunehmende Lähmung; im Mai intermittirende, demnächst remittirende Zustände. Zuckungen der Glieder, insbesondere der Finger. Brust-Symptome. Coma vigil. Intercurrent acutes Lungenödem, beseitigt durch Diuretica etc. Pneumonische Symptome. Tod am 16. Mai 1859.

Autopsie am 17. Mai: Hyperostose und Abflachung des Stirnbeins. Oedem, Trübung und ekchymotísche Flecken der weichen Häute. Vermehrte Adhärenz derselben an der Oberfläche des grossen Gehirns, besonders an den Stirnlappen. Hydrops ventriculorum. Granulationen im vierten Ventrikel. Oedem und mässige Erweichung der Gebirnsubstanz. Fettige Degeneration der Nervenzellen der inneren Lage der Corticalsubstanz der Grossbirn-Windungen. - Tuberkel und lobuläre Pneumonie der linken Lunge mit entsprechender Verdickung der Pleura. Mässige Erweiterung des Herzens, knotige Verdickungen der Semilunar-kiappen, Atheromasie und geringe Erweiterung der Aorta. - Melanose und Erweichung der Milz. Beginnende Fettdegeneration der Leber. -

Schriftprobe: „Die Fröschesen-Trppen konnten kaum das offene Feld behaupten, geschweige das Sie vermocht $n$ hätten, vollständig alle Haupt Punkte zu 
besesesesezen. Moncey muste sich vor Vallencia zurüken ziehen, Genral Düpont und Wedel wurden in Andalusien umzingelt und dann ge-schlagen und gefangen. Auch die Belagergung von Sarragossa musten die Franzosen aufgeben, ja Sturm und Verwürwürwürung wuchsen zu einer Stärke, dass der König Josephe aus Madrid nach Vittorigiga floh und ängstlich auf Hülfe von Seinem Bruder warteten, "

Durch die im Vorstehenden gegebene vergleichende Analyse dürfte der fundamentale Unterschied, welchen die beiden besprochenen Blödsinnsformen sowohl vom klinischen als anatomischen Standpunkte darbieten, deutlich genug hervorgetreten sein. Derselbe lässt sich kurz dahin zusammenfassen: Hier fester, wenn auch verringerter Bestand, dort allgemeine Lösung und Auflösung. Man wird auch leicht begreifen, dass es sich bei dem paralytischen Blödsinne nicht um einen umschriebenén Defect von stationärem Charakter und ebensowenig blos um einen dem Gehirn von Aussen mitgetheilten Erregungszustand dynamischer Art handelt, sondern um einen fortschreitenden Prozess, um eine ausgedehnte Modification der constituirenden Elementartheile im Gehirne selbst, um einen dauernden und die Integrität der organischen Theile in Frage stellenden Irritationszustand.

Die vorstehenden Ausführungen machen keineswegs den Anspruch erschöpfend zu sein. Es war hier meine Absicht nur, den wesentlichen Charakter des paralytischen Blödsinns in seinen allgemeinsten Grundzügen vergleichsweise möglichst anschaulich und fasslich hervorzuheben und zugleich die organische Begründung desselben im Auge zu behalten; und wenn man das gezeichnete Bild nicht für jeden einzelnen Fall congruent finden wird, so wird man sich erinnern müssen, dass sich die geistige Zerrüttung beim paralytischen Blödsinn allmälig vollzieht, eben weil derselbe kein stationärer Zustand, sondern ein fortschreitender Prozess ist, und dass der Degenerationsprozess der Hirnrinde zwar in der Regel eine diffuse und weit verbreitete Ausdehnung und die Tendenz zur Verallgemeinerung hat, aber doch auch, was Intensität und räumliche Ausdehnung in den einzelnen Fällen betrifft, eine gewisse Mannichfaltigkeit zeigt *). Man wird desshalb aus einzelnen Zügen, die noch ein der Wirklichkeit a däquates Vorstellungsleben und einen ge- 
wissen geistigen Zusammenhalt documentiren, keinen durchgreifenden Einwand gegen die principielle Richtigkeit der gegebenen Darstellung herleiten dürfen.

Einen analogen Unterschied wie die geistige, bietet auch die körperliche Lähmung dar. Bei dem paralytischen Blödsinnigen ist die Motilitäts-Lähmung nicht stationär und localisirt, wie bei der Lampert, sondern allgemein, unvollständig, aber sich immer mehr vervollständigend. Die electromuskuläre Contractilität ist nicht verloren gegangen; aber es fehlt vor Allem das ordnende Princip und die Fähigkeit, die Muskelcontraction mit dem intendirten Zwecke in Einklang zu bringen und danach zu bemessen, weil auch auf diesem Gebiete das Maass, sowol für die zeitliche Dauer und Aufeinanderfolge als auch für die Ausgiebigkeit der einzelnen Contractionen verloren gegangen ist. Das Muskelcontractionsgefühl, welches den Muskelcontractionen bei Ausführung zweckdienlicher Bewegungen zum maassgebenden Principe dient, alle unsere Muskelcontractionen begleitet und die Leichtigkeit, Feinheit und Geschicklichkeit, das Abgerundete der Bewegungen bedingt, finden wir bei der allgemeinen Paralyse schon frühzeitig beeinträehtigt. Dann kommt aber auch die Verringerung der Innervation in Betracht. Zugleich ist die centrale cerebrale Influenz geschwächt, der Connex der Muskelbewegungen mit dem Willen gelockert. Wir begegnen demnach sowol auf motorischem als auch auf intellectuellem Gebiete (centrifugale und centripetale Energie des Gehirns) Veränderungen mit dem Charakter der Auflösung, Lockerung und Maasslosigkeit.

Was nun den Fall von Porencephalie an und für sich betrifft, so ist zumächst die Combination mit einem entsprechenden Defect im Cranium von Interesse. Fig. $\mathrm{C}$ der Taf. I. giebt einen geometrisch gezeichneten Umriss dieses Defects.

Ein ähnlicher Fall, welcher im 9ten Monat des Lebens durch einen Schlag auf den Kopf entstanden war und bei welchem die geistigen Fähigkeiten in der Hauptsache angeblich nicht gestört erschienen, ist von Alph. de St. Germain ${ }^{*}$ ) beschrieben worden.

*) Atrophie d'un hémisphère cérébral avec dilatation considérable du ventricule 
Ob aber die von Hrn. Prof. Heschl*) beobachteten resp. beschriebenen Fälle von Porencephalie, was die Aetiologie und die psychischen Störungen betrifft, mit dem von mir beobachteten in dieselbe Kategorie gehören, ist zweifelhaft, da in diesen Fällen Idiotie bestanden zu haben scheint, was in unserem Falle ebensowenig wie in dem von $S t$. Germain und einem anderen von Hrn. Dr. Tüngel**) mitgetheilten der Fall gewesen ist. Auch ist dort auf eine einseitige partielle Vorbauchung am Schädel als eines diagnostischen Hilfskriteriums hingewiesen. In unserem Falle war aber anstatt einer Knochenauftreibung eine Knochenlücke, ausser Porencephalie auch Porocranie vorhanden.

Der in unserem Falle beobachtete fallsüchtige Zustand ist wohl auf die anatomische Abnormität zurückzuführen. In dieser Beziehung ist vor Allem das Moment der Ungleichheit der Massen der beiden Hemisphären von Bedeutung, indem durch dieselbe das Gleichgewicht der Innervation in Frage gestellt erscheint.

Genaue und umfassende Untersuchungen über die Ungleichheit des Gewichts der Hemisphären des Gehirns sind besonders von Follet angestellt worden. In seinen "Considérations pratiques et théorétiques déduites de 300 autopsies faites de 1833-1854"“ constatirte er, dass er immer Gewichtsgleichbeit gefunden habe in allen Fällen, in denen keine Epilepsie oder Hemiplegie beobachtet wurde, dass hingegen bei den Epileptischen eine Gewichtsdifferenz nie gefehlt habe. Die gefundenen Differenzen schwankten zwischen $15-290 \mathrm{Grm}$. Als arithmetisches Mittel ergibt sich aus der Summe der Differenzen $=2534$ dividirt durcb die Zahl der Einzelfälle 50 ( 40 von Follet, 10 von Hrn. Baume 1854 bis 1855 beobachtet) $=50 \frac{3}{5} \frac{4}{0} \mathrm{Grm}$. Hr. B a ume $\mathrm{e}^{* * *}$ ) hat diese Beob-

latérale et disparition d'une partie des circonvolutions. Hémiplégie; accès d'épilepsie datant de la prémière année. - Intégrité des facultés intellectuelles et morales. Mort à quarante et un ans. Annal. méd.-psych. 1856. p. 613.

*) Prager Vierteljahresschrift 1859. Bd.61. S. 59. - Cit. in Griesinger, Pathologie u. Therapie der psychischen Krankheiten. 2. Aufl. S. 362.

**) Klin. Mittheilungen, Hamburg 1860. S. 65 .

***) Baume, De l'inégalité de poids entre les hémisphères cérébraux chez les épileptiques. Annal. méd.-psychol. 1862. p. 426. 
achtungen für den Zeitraum von 1856-1862 fortgesetzt und aus 20 Fällen eine mittlere Gewichtsdifferenz von $40 \mathrm{Grm}$. erhalten. Hr. Delasiauve fand als solche $22 \mathrm{Grm}$. (Journ. de méd. ment.). Dass aber auch, abgesehen von der Massendifferenz beider Hemisphären als solcher, durch den anomalen Zustand des grossen und kleinen Gehirns noch in anderer Weise Prädispositionen zu Innervationsstörungen gegeben sind, ist leicht ersichtlich.

\section{Erklärung der Abbildungen.}

Tafel I.

Fig. A. v. B. Mikroskopische Ansicht von zwei anf gleiche Weise behandelten und gleich stark (nahezu 50mal) vergrösserten Präparaten der Corticalsubstanz, die aus bleinen bis zu einem gewissen Grade getrockneten Stückchen der Grosshirnwindungen entnommen und mit Glycerin geklärt wurden:

A) von einem Paralytisch-Blödsinnigen, dessen Krankheitsgeschichte in der Abhandjung "Die paralyt. Geisteskrankheit a. ihre org. Grondl." V. 1. Beob. mitgetheilt worden ist.

B) von einer epileptischen und porencephalischen Blödsinnigen (s. die Krankheitsgeschichte S. 305).

z. Ohere Lage der Corticalsubstanz, in welcher man nur vereinzelte und kleine Zellenformationen angedeutet und einige Gefüssstämmchen von der Peripherie eindringen siebr.

y. Innere Lagen der Corticalsubstanz, mit zablreichen Nervenzellen versehen. In Fig. A erscheinen dieselben als d u n k le (in's Bräunliche fallende), in Fig. B dagegen als belle, feiner und schärfer contourirte Miniaturformationen. In beiden Präparaten macht sich eine radïäre, durch die gegen die 0 berfäche der Windungen aufsteigenden Faserbündel bedingte, Streifung bemerlich. Auch querverlaufende Faserzüge sieht man, inshesondere in Fig. A, durchscheinen.

w. Uehergang der Cortical- in die Medullar-Substanz.

a-u. Nervenzellen aus der inneren Lage der Corticalsubstanz des grossen Gehirns des Puralytisch-Blödsinnigen (den Zellen der in Fig. A mit y bezeichneten Schicht entsprechend) in verschiedenen Graden der fettig-pigmentösen Degeneration; $a-s$ bei 300 maliger, $t$ und a bei 500 maliger Vergrösserung gezeichnet. (In Fig. $\mathbf{p}$ ist eine neben dem Kern befindliche helle Partie zu scharf contourirt abgebildet, so dass zwei Kerne vorhanden zu sein scheinen。)

૨-v. Nervenzellen aus dem Gebirn des Paralytisch-Blödsinnigen nach Behandlung mit Weinsteinsäure (nach früher von mir angefertigten Zeichnungen copirt). Man sieht deutliche Kerntheilung, während der eigentlicbe Zellen- 
körper blasser und homogener geworden ist. Es sind weder Fett- noch Pigmentkörnchen zu sehen.

1-10. Nervenzellen aus entsprechenden Partien der Windungen des grossen Gebirns der erwähnten epileptischen Blölsinnigen (den als kleine helle Bläschen bemerkbaren Zellen der Schicht $y$ in Fig. B entsprechend) bei 300maliger Vergrösserung. Sie erscheinen sehr schwach granulirt, fein und scharflinig contourirt, blass, bell und mehr homogen glänzend, ohne bemerkenswerthe Pigment- und Fettiörnchen-Einlagerung.

Fig. C. Geometrisch gezeichneter Umriss der Lücke im rechten Seitenwandbein nach Maceration des Schädels. (S. den Fall von Porencephalie S. 307.)

\section{XIII.}

\section{Zurr Pathologie der epidemischen Meningitis.}

Von Dr. Klebs in Berlin.

Seit dem Anfange des vorigen Jahres ist in der Stadt Berlin die oben genannte Krankheit in epidemischer Verbreitung, soweit bekannt, zum ersten Mal aufgetreten. Durch die Güte ver: schiedener Collegen wurde mir die erwünschte Gelegenheit geboten, eine grössere Anzabl auch von solchen ausserhalb des Spitals vorgekommenen Fällen zu obduciren. Die dabei gewonnenen Erfahrungen sollen in dem Folgenden mitgetheilt werden, und ich denke, dass dieselben, auch ohne die Berücksichtigung der klinischen und historischen Verhältnisse, welche von competenterer Seite hoffentlich einer ausführlicheren Bearbeitung werden unterzogen werden, dennoch zur Aufstellung gewisser Gesichtspunkie nöthigen werden, welche das Verständniss dieses pathologischen Zustandes wenigstens anbabnen dürften.

Um zuvörderst eine Uebersicht über den Verlanf der Epidemie zu geben, lasse ich die beistehende Tabelle folgen, welche die durch die Section constatirten Fälle von acuter, primärer Meningitis enthält. Ein Theil derselben ist bereits anderweitig veröffentlicht*).

*) Frentzel, Ueber eine Epidemie von Meningitis cerebro-spinalis. Berl. klin. Wochenschr. 1864. No. 21, 22. Fischer und $\mathrm{H}$ of $\mathrm{fmann}$, ibidem. No. 36. 